\title{
Article \\ A Molecular Shape Recognitive HPLC Stationary Phase Based on a Highly Ordered Amphiphilic Glutamide Molecular Gel
}

\author{
Naoki Kawamoto ${ }^{1}$, Yongxing $\mathrm{Hu}^{1}$, Yutaka Kuwahara ${ }^{1}\left(\mathbb{D}\right.$, Hirotaka Ihara ${ }^{1,2, *(\mathbb{D})}$ and Makoto Takafuji ${ }^{1, *(\mathbb{D})}$ \\ 1 Department of Applied Chemistry and Biochemistry, Kumamoto University, 2-39-1 Kurokami, Chuo-ku, \\ Kumamoto 860-8555, Japan; nakpmw@gmail.com (N.K.); 192d9403@st.kumamoto-u.ac.jp (Y.H.); \\ kuwahara@kumamoto-u.ac.jp (Y.K.) \\ 2 National Institute of Technology, Okinawa College, 905 Henoko, Nago, Okinawa 905-2192, Japan \\ * Correspondence: ihara@kumamoto-u.ac.jp (H.I.); takafuji@kumamoto-u.ac.jp (M.T.); \\ Tel.: +81-96-342-3661 (H.I.)
}

Citation: Kawamoto, N.; Hu, Y.; Kuwahara, Y.; Ihara, H.; Takafuji, M. A Molecular Shape Recognitive HPLC Stationary Phase Based on a Highly Ordered Amphiphilic Glutamide Molecular Gel. Nanomaterials 2021, 11, 1574. https:// doi.org/10.3390/nano11061574

Academic Editor: Pablo Guardia

Received: 29 April 2021

Accepted: 12 June 2021

Published: 15 June 2021

Publisher's Note: MDPI stays neutral with regard to jurisdictional claims in published maps and institutional affiliations.

Copyright: (c) 2021 by the authors. Licensee MDPI, Basel, Switzerland. This article is an open access article distributed under the terms and conditions of the Creative Commons Attribution (CC BY) license (https:// creativecommons.org/licenses/by/ $4.0 /)$.

\begin{abstract}
Chiral glutamide-derived lipids form self-assembled fibrous molecular gels that can be used as HPLC organic phases. In this study, HPLC separation efficiency was improved through the addition of branched amphiphilic glutamide lipids to the side chains of a terminally immobilized flexible polymer backbone. Poly(4-vinylpyridine) with a trimethoxysilyl group at one end was grafted onto the surface of porous silica particles $\left(\mathrm{Sil}-\mathrm{VP}_{15}\right.$, polymerization degree $\left.=15\right)$, and the pyridyl side chains were quaternized with a glutamide lipid having a bromide group $(\mathrm{Br} G)$. Elemental analysis indicated that the total amount of the organic phase of the prepared stationary phase (Sil-VPG 15 ) was $38.0 \mathrm{wt} \%$, and the quaternization degree of the pyridyl groups was determined to be $32.5 \%$. Differential scanning calorimetric analysis of a methanol suspension of Sil-VPG ${ }_{15}$ indicated that the $G$ moieties formed a highly ordered structure below the phase transition temperature even on the silica surface, and the ordered $G$ moieties exhibited a gel-to-liquid crystalline phase transition. Compared with a commercially available octadecylated silica column, the Sil-VPG 15 stationary phase showed high selectivity toward polycyclic aromatic hydrocarbons, and particularly excellent separations were obtained for geometrical and positional isomers. Sil-VPG 15 also showed highly selective separation for phenol derivatives, and bio-related molecules containing phenolic groups such as steroids were successfully separated. These separation abilities are probably due to multiple interactions between the elutes and the highly ordered functional groups, such as the pyridinium and amide groups, on the highly ordered molecular gel having self-assembling $G$ moieties.
\end{abstract}

Keywords: high performance liquid chromatography (HPLC); molecular gels; highly-oriented structure; stereo isomers; phenolic compounds; steroids

\section{Introduction}

High performance liquid chromatography (HPLC) has been widely used for the analysis and separation of organic compounds containing polymers and bio-molecules, because it is convenient and quick analytical technique. The development of HPLC stationary phases is of importance to expand its applicability in various fields. So far, various surface-modified porous silica particles having organic phases such as ionic liquid analogues [1-5], synthetic polymers [6,7], oligo-peptides [8-10], and carbon materials [11-13] have been developed for practical use as HPLC stationary phases. These organic phases show high selectivity toward for samples that are difficult to separate with conventional octadecylated-porous silica (ODS) in reversed-phase HPLC because of their unique interaction sites. Steric arrangement of the interaction sites is effective to enhance the selectivity of the guest molecules. The organic phase of ODS recognizes molecular hydrophobicity in reversed phase HPLC (RP-HPLC) mode which brings separation of guest molecules by partition mechanism. It has been reported that the selectivity toward polyaromatic 
hydrocarbons (PAHs) and their isomers can be enhanced by increasing of grafting-density of the octadecyl groups on the silica surface $[14,15]$.

Molecular gels have been attracting significant attention because their highly oriented structures result in unique properties [16-21]. L-Glutamide derived molecules form self-assembled molecular gels in aqueous and organic media that exhibit specific functions such as supramolecular chirality and supramolecular fluorescence [22-28]. The amphiphilic glutamide derivatives formed nanosized fibrous aggregates based on lipid bilayer membranes with unique morphological features such as nanotubes and nanohelices $[17,26,27]$. In organic solvent, lipophilic glutamide derivatives formed low molecular weight organogels composed of 3-dimensional fibrous aggregate network [17,28]. These aggregates formed from the glutamide-derivatives with chromophore group showed unique optical properties such as induced circular dichroism and circularly polarized luminescence, and emission with large Stokes shift based on the highly-oriented structure with chiral arrangement $[19,22-25,28]$.

The highly oriented structure of the self-assembled molecular gels can recognize the molecular shape of guest molecules through multiple interactions using regularly arranged functional groups. Directly immobilized lipophilic glutamide derivatives on the surface of silica microspheres recognize polycyclic aromatic hydrocarbons (PAHs), particularly the molecular planarity and the molecular length of PAHs [29-32]. We reasoned that the high selectivity of the glutamide derivatives toward guest molecules occurred through multiple interactions with the highly ordered carbonyl groups on the self-assembly. In this study, we improved the molecular orientation of the glutamide moiety by introducing it to the side chain of a flexible polymer that was immobilized on a silica surface. We then examined the molecular recognition behavior of this material as a high-performance liquid chromatography (HPLC) stationary phase.

\section{Materials and Methods}

2.1. Stabilization of Glutamide-Derived Lipid-Branched Polymers on Porous Silica (Sil-VPG $\left.{ }_{15}\right)$

\subsubsection{Materials and Instruments}

Porous silica microspheres $\left(\mathrm{YMC}^{*} \mathrm{GEL}\right.$, diameter $=5 \mu \mathrm{m}$, average pore size $=12 \mathrm{~nm}$, specific surface area $\left.=330 \mathrm{~m}^{2} \mathrm{~g}^{-1}\right)$ for the stationary phase were purchased from YMC Co. Ltd. (Kyoto, Japan). All other chemicals used for the synthesis of Sil-VPG 15 were purchased from Tokyo Chemical Industry Co., Ltd. (Tokyo, Japan), Fujifilm Wako Pure Chemical Co. (Osaka, Japan), Nacalai Tesque, Inc. (Kyoto, Japan), and Sigma-Aldrich Japan (Tokyo, Japan), and were purified before use as needed.

${ }^{1} \mathrm{H}-\mathrm{NMR}$ spectra were recorded at $400 \mathrm{MHz}$ in $\mathrm{CDCl}_{3}$ at $25^{\circ} \mathrm{C}$ using a JEOL JNMLA400 spectrometer (JEOL Ltd., Tokyo, Japan). Chemical shifts $(\delta)$ are expressed in parts per million (ppm) using tetramethylsilane (TMS) as an internal standard $(\delta=0.0 \mathrm{ppm})$. FT-IR spectra were obtained with a JASCO FT/IR-4100 spectrometer (JASCO Co., Tokyo, Japan). A DR PRO410-M accessory (JASCO Co.) was used for diffuse reflectance FT-IR (DRIFT) measurements. Elemental analyses were carried out on a CHN Corder MT-6 Apparatus (Yanaco Analytical Systems Inc., Kyoto, Japan). Differential scanning calorimetry was performed using DSC 7000 (Hitachi High-Tech Science Co., Tokyo, Japan). The aluminum open pan and the silver closed cell were used for solid state samples and suspension state samples respectively. The measurements were carried out the heating rate of $2{ }^{\circ} \mathrm{C} \min ^{-1}$ under the $\mathrm{N}_{2}$ gas atmosphere. The surface charge of the particles in suspension state were detected by Zetasizer Nano ZS (Malvern Panalytical Ltd., Kobe, Japan).

\subsubsection{Synthesis of Glutamide-Derived Lipid}

The glutamide-derived lipid, $N^{1}, N^{2}$-didodecyl-L-glutamide $(G)$ was synthesized according to our previous report [33]. The glutamide $G(4.50 \mathrm{~g}, 0.93 \mathrm{mmol})$ and 11bromoundecanoic acid $(3.42 \mathrm{~g}, 1.17 \mathrm{mmol})$ were dissolved in chloroform $(300 \mathrm{~mL})$, and the mixture was stirred in an ice bath. Triethylamine $(3.58 \mathrm{~mL}, 25.8 \mathrm{mmol})$ and diethyl cyanophosphate $(2.08 \mathrm{~mL}, 12.4 \mathrm{mmol})$ were added to the mixture, which was then stirred 
for $1 \mathrm{~h}$ in an ice bath and then for $24 \mathrm{~h}$ at $25^{\circ} \mathrm{C}$. The mixture was washed with $0.3 \mathrm{~mol} \mathrm{~L}-1$ aqueous $\mathrm{HCl}$ solution (3 times), $5 \mathrm{wt} \%$ aqueous $\mathrm{NaHCO}_{3}$ solution (3 times), and deionized water ( 3 times). The solution was dried over anhydrous sodium sulfate. After removal of the sodium sulfate by filtration, the chloroform was removed by evaporation under reduced pressure. The residue was recrystallized from ethanol, and the precipitate was collected by filtration and dried in vacuo to obtain white crystals ( $\mathrm{BrG}$, Scheme 1). Yield: $6.77 \mathrm{~g}(89.7 \%)$, $\mathrm{mp}: 123.5-124.4^{\circ} \mathrm{C}$. FT-IR (KBr): $3291 \mathrm{~cm}^{-1}\left(v_{\mathrm{N}-\mathrm{H}}\right), 2923 \mathrm{~cm}^{-1}\left(v_{\mathrm{C}-\mathrm{H}}\right), 2856 \mathrm{~cm}^{-1}\left(v_{\mathrm{C}-\mathrm{H}}\right)$, $1637 \mathrm{~cm}^{-1}\left(v_{\mathrm{N}-\mathrm{H}}(\right.$ amide $\left.)\right), 1557 \mathrm{~cm}^{-1}\left(v_{\mathrm{N}-\mathrm{H}}\right) .{ }^{1} \mathrm{H}-\mathrm{NMR}: \delta 0.86-0.90\left(\mathrm{t}, 6 \mathrm{H}, \mathrm{CH}_{3}\right), \delta 1.24(\mathrm{br}$, $48 \mathrm{H},\left(\mathrm{CH}_{2}\right){ }_{9} \mathrm{CH}_{3}$ and $\left.\mathrm{BrCH}_{2} \mathrm{CH}_{2}\left(\mathrm{CH}_{2}\right)_{6}\right), \delta 1.39-1.44\left(\mathrm{~m}, 2 \mathrm{H}, \mathrm{C}(=\mathrm{O}) \mathrm{CH}_{2} \mathrm{CH}_{2}\right), \delta 1.49-1.53$ $\left(\mathrm{m}, 4 \mathrm{H}, \mathrm{NHCH}_{2} \mathrm{CH}_{2}\right), \delta 1.81-1.88\left(\mathrm{~m}, 2 \mathrm{H}, \mathrm{C}^{*} \mathrm{HCH}_{2}\right), \delta 1.92-2.10\left(\mathrm{~m}, 2 \mathrm{H}, \mathrm{C}^{*} \mathrm{HCH}_{2} \mathrm{CH}_{2}\right), \delta$ 2.19-2.31 (m, 2H, COCH $\mathrm{CH}_{2}, \delta$ 2.41-2.48 (m, 2H, BrCH $\left.\mathrm{CH}_{2}\right), \delta 3.20-3.30\left(\mathrm{dt}, 4 \mathrm{H}, \mathrm{NHCH}_{2}\right)$, $\delta 3.38-3.42\left(\mathrm{t}, 2 \mathrm{H}, \mathrm{BrCH}_{2}\right), \delta 4.30-4.36\left(\mathrm{dt}, 1 \mathrm{H}, \mathrm{C}^{*} \mathrm{H}\right), \delta 6.02-6.05(\mathrm{t}, 1 \mathrm{H}, \mathrm{NH}), \delta 6.82-6.85$ $(\mathrm{t}, 1 \mathrm{H}, \mathrm{NH}), \delta 6.99-7.01(\mathrm{~d}, 1 \mathrm{H}, \mathrm{NH})$. Elemental analysis Calcd. (\%) for $\mathrm{C}_{40} \mathrm{H}_{78} \mathrm{BrN}_{3} \mathrm{O}_{3}: \mathrm{C}$ 65.91, H 10.79, N 5.76; Found: C 64.91, H 11.76, N 5.62.

\subsubsection{Preparation of Poly(4-Vinylpyridine)-Grafted Porous Silica}

A mixture of 4-vinylpyridine $(10.51 \mathrm{~g}, 100 \mathrm{mmol})$ and 3-mercaptopropyltrimethoxysilane $(0.98 \mathrm{~g}, 5 \mathrm{mmol})$ was stirred with nitrogen gas bubbling through the solution for $20 \mathrm{~min}$. Then, 2,2'-azobis(isobutyronitrile) (105 $\mathrm{mg}, 1 \mathrm{wt} \%$ of 4 -vinylpyridine) was added, and the mixture was stirred at $60{ }^{\circ} \mathrm{C}$ under a nitrogen atmosphere for $3 \mathrm{~h}$. The obtained pale yellow viscous solution was dissolved in a small amount of chloroform, and the solution was added dropwise to diethyl ether. The precipitate that formed was washed with diethyl ether, dried in vacuo, and the product was obtained as a white powder. Yield: $7.10 \mathrm{~g}(67.6 \%) .{ }^{1} \mathrm{H}-\mathrm{NMR}: \delta$ 0.5-0.7 (m, 2H, Si-CH $\left.{ }_{2}\right), \delta 3.4-3.6\left(\mathrm{~s}, 9 \mathrm{H}, \mathrm{Si}-\mathrm{OCH}_{3}\right), \delta$ 6.1-7.0 (m, 4H, 2- and 6-positions of pyridyl group), $\delta 8.1-8.7(\mathrm{~m}, 4 \mathrm{H}, 3-$ and 5-positions of pyridyl group). The average polymerization degree of the poly(4-vinylpyridine) with a trimethoxysilyl reactive group at one terminus was determined to be $15\left(\mathrm{VP}_{15}\right)$ from the integral ratio of the peaks of the methylene group at the $\gamma$-position of the terminal 3-mercaptopropyltrimethoxysilane and the pyridine ring.

$\mathrm{VP}_{15}(2.0 \mathrm{~g})$ was dissolved in chloroform $(35 \mathrm{~mL})$ in a three-neck flask. Porous silica microspheres $(4.0 \mathrm{~g})$ were added to the solution and gently stirred at reflux for 3 days. The resulting surface-modified silica microspheres were filtered and washed with chloroform, then dried in vacuo $\left(\right.$ Sil- $\mathrm{VP}_{\mathrm{n}}$, Scheme 1$)$.

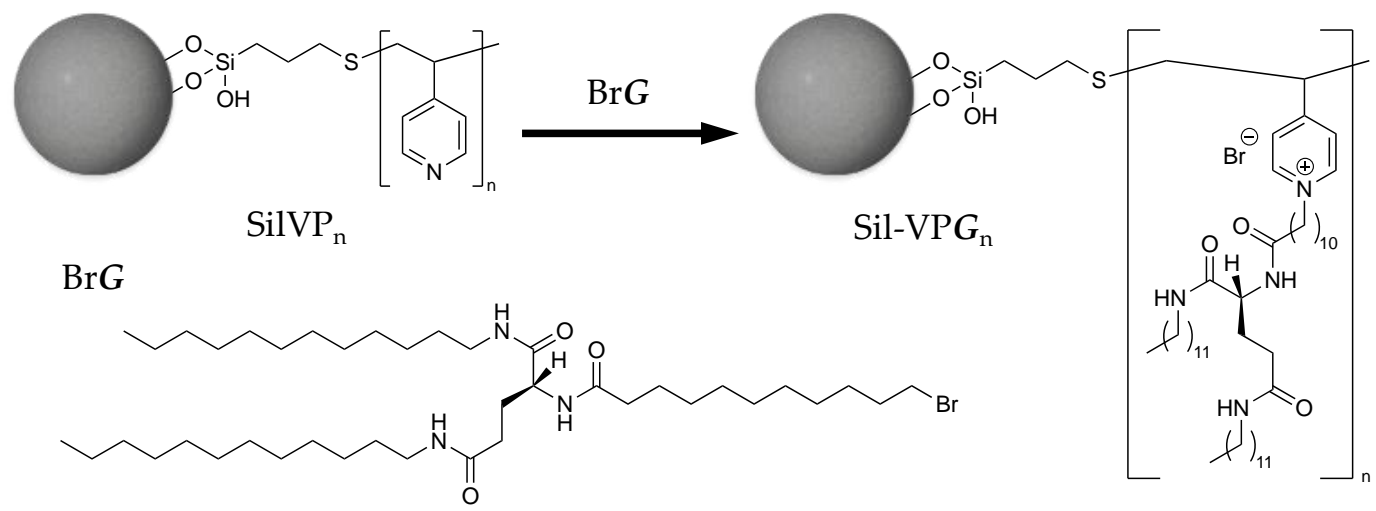

Scheme 1. Chemical structures of Sil- $\mathrm{VP}_{15}, \mathrm{Br} G$, and Sil-VPG 15 .

\subsubsection{Quaternization of Pyridyl Side Chains with Glutamide-Derived Lipid}

Sil- $\mathrm{VP}_{15}(3.0 \mathrm{~g})$ and $\mathrm{BrG}(7.01 \mathrm{~g})$ were added to toluene $(30 \mathrm{~mL})$, and the mixture was heated at reflux for 3 days with stirring. The product was collected by filtration through a glass filter, washed with toluene, chloroform, and methanol, in that order, and dried under reduced pressure to obtain Sil-VPG 15 (Scheme 1). 


\subsection{HPLC Performance of Sil-VPG 15 as the Stationary Phase}

\subsubsection{Chemicals}

All chemicals for HPLC analysis such as PAHs, phenolic derivatives, and steroids were obtained from TCI Co. Ltd. (Tokyo, Japan), Fujifilm Wako Pure Chemical Co. (Osaka, Japan), and Sigma-Aldrich Japan Inc. (Tokyo, Japan). HPLC-grade solvents were used for chromatographic separations. Octadecyl-functionalized porous silica particles (Inertsil ODS-3 packed column) were purchased from GL Science Inc. (Tokyo, Japan) and used as a reference stationary phase.

\subsubsection{Chromatographic Procedures}

Sil- $\mathrm{VPG}_{15}$ was packed into stainless steel columns ( $150 \mathrm{~mm} \times 4.6 \mathrm{~mm}$ i.d.). Liquid chromatography was performed with acrylonitrile as the mobile phase at a flow rate of $1.0 \mathrm{~mL} \mathrm{~min}^{-1}$ under isocratic conditions. The chromatographic system included a JASCO 2089 pump and a JASCO MD-910 UV-Vis photodiode array detector. A $5 \mu \mathrm{L}$ sample was injected through a Rheodyne Model 7725 injector (IDEX Health \& Science, LLC, Middleboro, MA USA) having a $20 \mu \mathrm{L}$ loop. The column temperature was maintained using a column jacket. A personal computer connected to the detector with JASCO-Borwin (Ver 1.5) software was used for system control and data analysis. The separation factor $(\alpha)$ was determined by the ratio of retention factors $(k)$. The retention time of $\mathrm{D}_{2} \mathrm{O}$ was used as the void volume $\left(\mathrm{t}_{0}\right)$ marker. (The absorption for $\mathrm{D}_{2} \mathrm{O}$ was measured at $400 \mathrm{~nm}$, which is actually considered to be injection shock.)

\section{Results and Discussion}

3.1. Characterization of Amphiphilic Glutamide-Based Molecular Gel on the Porous Silica Particle 3.1.1. Grafting of Amphiphilic Glutamide-Based Molecular Gel

Poly(4-vinylpyridine) with a reactive group at one terminus $\left(\mathrm{VP}_{\mathrm{n}}\right)$ was prepared by telomerization of 4-vinylpyridine using 3-mercaptopropyltrimethoxysilane as a telogen.

The polymerization degree (n) was determined to be 15 . In our previous report, we confirmed that the separation behavior of the polymer-immobilized porous silica was almost the same in the polymer having a degree of polymerization of 10 or more [34]. The obtained $\mathrm{VP}_{15}$ was immobilized on the spherical porous silica with an average particle size of $5 \mu \mathrm{m}$ and an average pore size of $12 \mathrm{~nm}$, which is commonly used for HPLC packing material. The grafting amount of $\mathrm{VP}_{15}$ on the surface of the porous silica was determined by elemental analysis to be $17.2 \mathrm{wt} \%$.

The quaternization reaction of the pyridyl side chain was confirmed by the FT-IR spectrum (Figure 1), in which the peaks of the $\mathrm{C}=\mathrm{C}$ and $\mathrm{C}=\mathrm{N}$ stretching vibrations of the pyridine ring shifted from 1600 to $1640 \mathrm{~cm}^{-1}$ and from 1417 to $1467 \mathrm{~cm}^{-1}$, respectively [35,36]. In addition, a C-H stretching band at approximately $2850-2950 \mathrm{~cm}^{-1}$ that was due to the long alkyl chain of the $G$ moiety appeared after quaternization.

Elemental analysis of the polymer-grafted porous silica (Table 1) showed an increase in the amount of the organic phase accompanied by an increase in the $\mathrm{C} / \mathrm{N}$ ratio from 6.1 to 8.7. From these results, the percentage quaternization of the pyridyl groups with $\mathrm{Br} G$ was calculated as $32.5 \%$. Because the pyridinium salt after quaternization is cationic, success of the quaternization reaction was also determined by measuring the zeta potential at the particle interface, which confirmed that the particle interface of Sil-VPG ${ }_{15}$. was more positively charged than Sil- $\mathrm{VP}_{15}$.

Thermogravimetric analysis of Sil- $\mathrm{VP}_{15}$ and Sil- $\mathrm{VPG}_{15}$ (Figure 2), in which the amount of the organic phase increased from $17.2 \mathrm{wt} \%$ before quaternization to $38.0 \mathrm{wt} \%$ after quaternization, supported this conclusion. SEM images of the porous silica particles before (Sil) and after polymer grafting $\left(\mathrm{Sil}-\mathrm{VP}_{15}\right)$ and quaternization (Sil-VPG ${ }_{15}$ ) showed no noticeable change in appearance of the spherical shape, which indicated that the polymer grafting and quaternization had occurred on the surface of the porous silica particles. 
Table 1. Elemental analysis of Sil- $\mathrm{VP}_{15}$ and Sil-VPG 15 .

\begin{tabular}{ccccccc}
\hline Stationary Phase & & $\mathbf{C} \%$ & $\mathbf{H} \%$ & $\mathbf{N} \%$ & $\mathbf{C} / \mathbf{N}$ & Organic Phase (wt\%) $^{2}$ \\
\hline \multirow{2}{*}{ Sil- $-\mathrm{VP}_{15}$} & Found & 13.4 & 1.73 & 2.18 & 6.13 & \multirow{2}{*}{17.2} \\
& Calcd $^{1}$ & 15.7 & 1.37 & 2.56 & 6.13 & \multirow{2}{*}{ Sil-VPG } \\
& Found $_{15}$ & 27.6 & 4.48 & 3.18 & 8.68 & \\
& Calcd $^{2}$ & 28.7 & 3.89 & 3.31 & 8.67 & \\
\hline
\end{tabular}

${ }^{1}$ Calcd. for $\mathrm{C}_{108} \mathrm{H}_{112} \mathrm{SN}_{15}$ (17.2 wt \% of organic phase). ${ }^{2}$ Calcd. for $\mathrm{C}_{303} \mathrm{H}_{494} \mathrm{~N}_{420} \mathrm{O}_{240} \mathrm{~S}_{32}$ (38.0 wt $\%$ of organic phase).

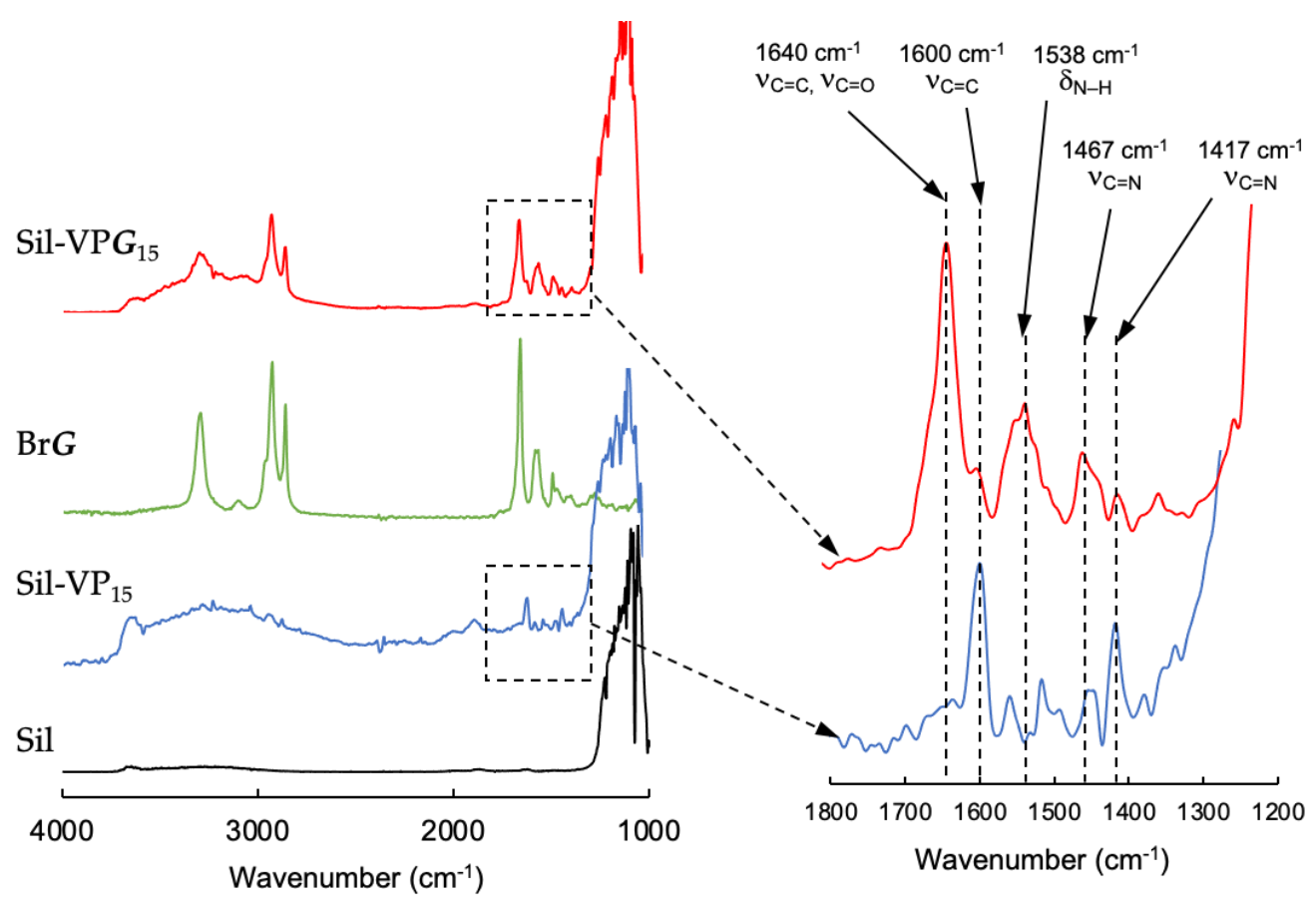

Figure 1. Diffuse reflectance FT-IR spectra of Sil, Sil-VP $15, \mathrm{BrG}$, and Sil-VPG 15 .

(a)
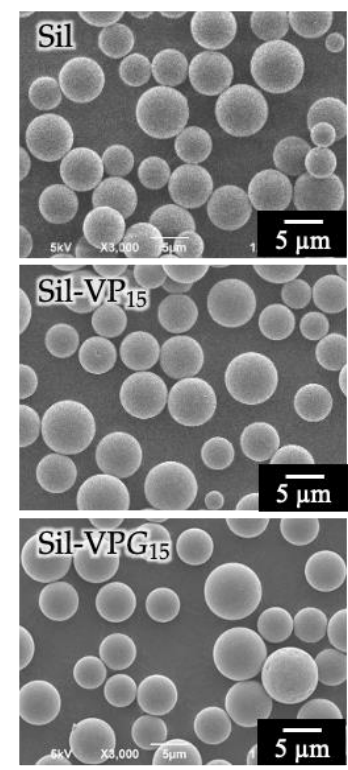

(b)

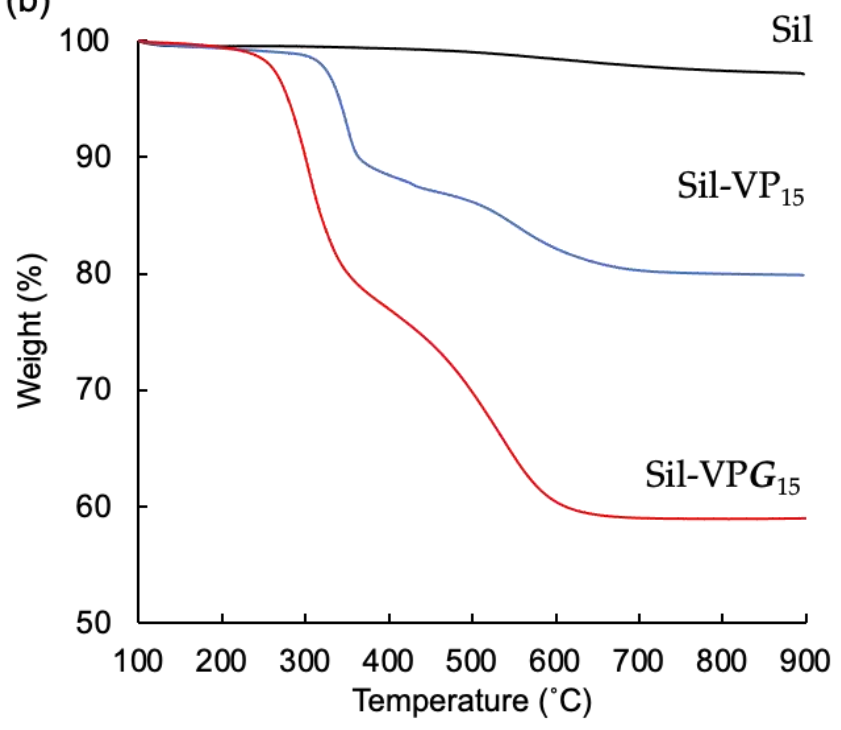

Figure 2. (a) SEM images and (b) DSC thermograms of Sil, Sil- $\mathrm{VP}_{15}$, and Sil-VPG 15 . The particles were coated with osmium for the SEM observations. Heating rate for DSC: $10^{\circ} \mathrm{C} \mathrm{min}^{-1}$. 


\subsubsection{Evaluation of Amphiphilic Glutamide-Based Molecular Gels on the Silica Surface}

The obtained Sil-VPG 15 could be dispersed in organic solvents such as methanol and acetonitrile. The surface charge of the porous silica particles was $-11.4 \mathrm{mV}$ in methanol, which changed to +7.7 after $\mathrm{VP}_{15}$ grafting $\left(\mathrm{Sil}-\mathrm{VP}_{15}\right)$ and +32.8 after quaternization with $\mathrm{Br} G\left(\mathrm{Sil}-\mathrm{VPG} \mathrm{G}_{15}\right)$. These results suggest that the surface of Sil-VPG ${ }_{15}$ is amphiphilic and positively charged.

The DSC thermogram of Sil-VPG 15 in the solid state (Figure 3a) showed an endothermic peak at $68.8^{\circ} \mathrm{C}$, indicating that the $\mathrm{G}$ moiety of the side chain can form a crystalline structure on the surface of the silica. Since the melting point of $\mathrm{BrG}\left(123.5-124.4{ }^{\circ} \mathrm{C}\right)$ is higher than $68.8^{\circ} \mathrm{C}$, it is likely that the crystallization of the $\mathrm{G}$ moiety is perturbed by the polymer backbone. For Sil- $\mathrm{VPG}_{15}$ dispersed in acetonitrile, phase transition behavior was observed at $42.4^{\circ} \mathrm{C}$ with a pre-transition at $23.1^{\circ} \mathrm{C}$ (Figure $3 \mathrm{~b}$ ). According to our previous work, the amphiphilic glutamide derivative with a pyridinium terminal group showed phase transitions at $33^{\circ} \mathrm{C}$ (pre-transition) and $45^{\circ} \mathrm{C}$ (main transition), which were due to the rearrangement of intermolecular hydrogen bonds between amide bonds and the gelto-liquid crystalline phase transition of the G moiety, respectively [17]. And the lipophilic glutamide derivative showed a gel-to-dispersion (solution) phase transition in organic solvents [17]. The aggregation morphology and the orientation structure of amphiphilic and lipophilic G-derived molecules are strongly affected by the solvent [17,26-28]. It is notable that the highly ordered structure of the $\mathrm{G}$ moiety was maintained while on the polymer side chain of the terminally grafted polymer on the surface of the silica substrate

(a) in solid state

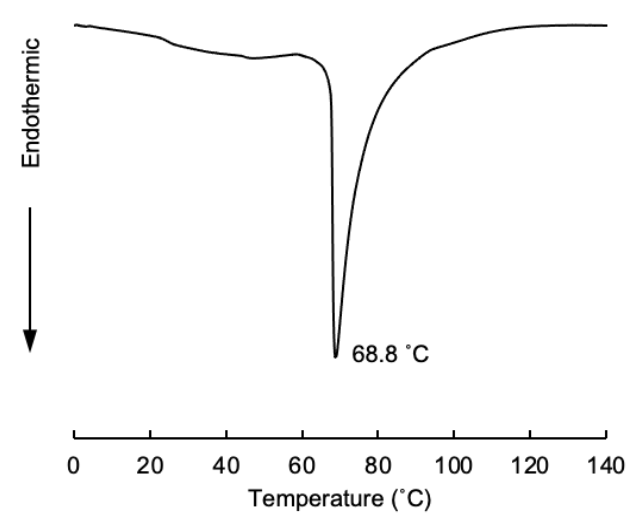

(b) in dispersion state (acetonitrile)

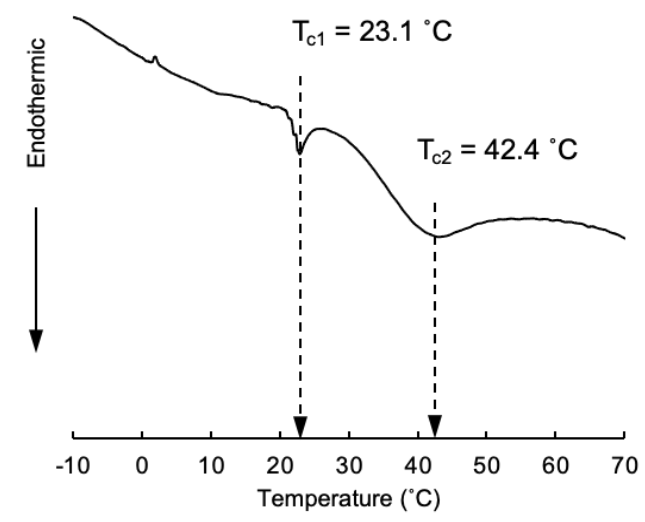

Figure 3. DSC thermograms of Sil- $\mathrm{VPG}_{15}(\mathbf{a})$ in the solid state and (b) in the suspension state (acetonitrile). Heating rate: $2{ }^{\circ} \mathrm{C} \min ^{-1}$ for the solid state and $1{ }^{\circ} \mathrm{C} \mathrm{min}^{-1}$ for the suspension state.

\subsection{HPLC Performance of Amphiphilic Glutamide-Based Molecular Gel \\ 3.2.1. Evaluation of Sil-VPG 15 as an HPLC Stationary Phase}

The $G$ moiety of Sil $-V P G_{15}$ possesses hydrophobic long alkyl chains and amide bonds, which were introduced to the side chain of the poly(vinylpyridine) through a quaternization reaction. The amphiphilic side chains of the $G$ moiety formed highly ordered structures on the silica surface even in polar organic solvents such as acetonitrile. Therefore, Sil-VPG 15 was evaluated as a packing material in RP-HPLC retention studies using alkylbenzenes and PAHs as analytes. Octadecylated porous silica microspheres (ODS), which are commonly used for the stationary phase in RP-HPLC, were used as a reference. Figure 4 shows the relationship between $\log \mathrm{k}\left(\mathrm{k}=\left(\mathrm{t}-\mathrm{t}_{0}\right) / \mathrm{t}_{0}\right.$, where $\mathrm{k}$ is the retention factor, $\mathrm{t}$ is the retention time of the elute, and $\mathrm{t}_{0}$ is the void volume) and $\log \mathrm{P}(\mathrm{P}$ is the 1-octanol-water partition coefficient) for ODS and Sil-VPG 15 . The $\log \mathrm{k}$ and $\log \mathrm{P}$ plots of the alkylbenzenes and PAHs in ODS were almost identical. However, Sil-VPG 15 showed a higher retention for PAHs than for alkylbenzenes. These results provided evidence that the ODS stationary 
phase can recognize only the hydrophobicity of the analytes, but Sil-VPG 15 has specific interaction sites as well as molecular hydrophobicity for the retention of PAHs.

(a)

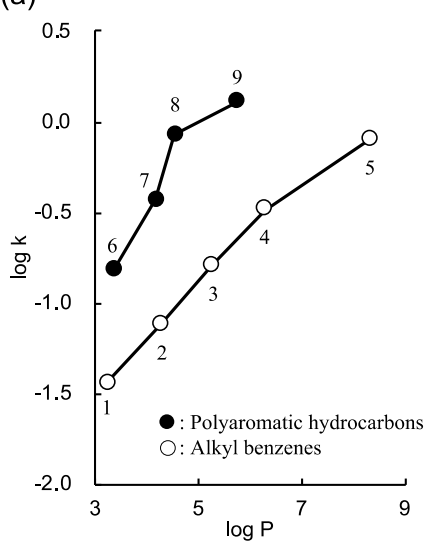

(b)

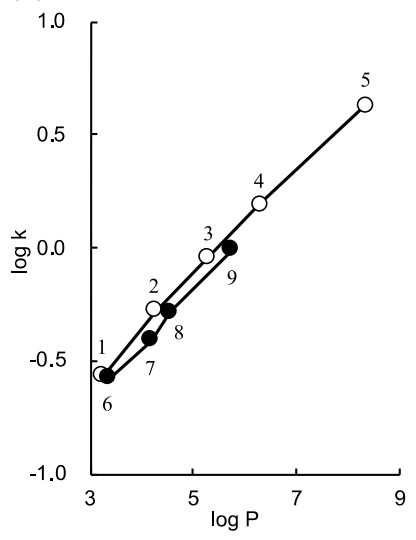

1: Ethylbenzene $(\mathrm{n}=2)$

2: Butylbenzene $(n=4)$

3: Hexylbenzene $(\mathrm{n}=6)$

4: Octylbenzene $(\mathrm{n}=8)$

5: Dodecylbenzene $(n=12)$

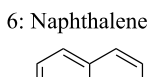

8: Anthracene
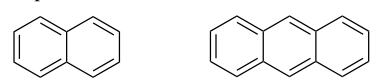

7: Fluorene

9: Naphthacene
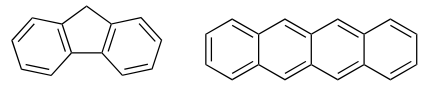

Figure 4. Relationships of $\log \mathrm{k}$ and $\log \mathrm{P}$ for (a) Sil-VPG 15 and (b) ODS. Mobile phase: Acetonitrile. Flow rate: $1.0 \mathrm{~mL} \mathrm{~min}{ }^{-1}$. Detection wavelength: $254 \mathrm{~nm}$. Column temp.: $25^{\circ} \mathrm{C}$.

We had previously reported that carbonyl group-containing stationary phases recognize the aromaticity of the elutes through carbonyl $\pi$-benzene $\pi$ interactions [37-39]. Particularly highly ordered carbonyl groups can recognize the molecular planarity and the molecular length of PAHs as well. Sil-VPG 15 also probably recognizes the $\pi$-electrons of the PAHs through multiple interactions with the ordered carbonyl groups on the oriented $G$ moieties.

\subsubsection{Temperature Dependence of the Separation Factors for PAH Isomers}

We previously reported that self-assembling molecule-immobilized stationary phases, in which the glutamide derivative is directly grafted to the porous silica particles through a siloxane linkage, show high selectivity toward PAHs [29-32]. Compared with these stationary phases, the self-assembling $G$ moiety may have relatively less perturbation from the silica surface because the flexible polymer chain is branched. Figure 5 shows the chromatograms for cis- and trans-stilbene; $o-, m-$, and $p$-sterphenyl; and triphenylene using Sil-VPG 15 and a commercially available ODS. Sil-VPG 15 showed baseline separations for these isomers whereas the ODS did not.

The retention and separation factors of these molecules using Sil-VPG 15 and ODS at $0{ }^{\circ} \mathrm{C}$ and $50{ }^{\circ} \mathrm{C}$ are summarized in Table 2 . The isomers were eluted earlier using the Sil- $\mathrm{VPG}_{15}$ stationary phase than they were using the ODS stationary phase, which is probably due to the amphiphilic nature of organic phase. However, Sil-VPG 15 showed extremely high selectivity toward these isomers at temperatures below $\left(0{ }^{\circ} \mathrm{C}\right)$ and above $\left(50^{\circ} \mathrm{C}\right)$ its phase transition. These results indicate that the $G$ moiety recognizes molecular shape even in a disordered state, and this is enhanced through orientation of the $G$ moiety.

The temperature dependency of the separation factors of naphthacene/fluorene, transstilbene/cis-stilbene, and triphenylene/o-terphenyl are shown in Figure 6 . The $\alpha$ value increased with decreasing temperature, and increased sharply below around $20^{\circ} \mathrm{C}$, which corresponds to the temperature of the pre-phase transition. In each case, planar molecules eluted later than non-planar molecules. This may be an effect of the orientation of the $G$ moiety. 
(a)

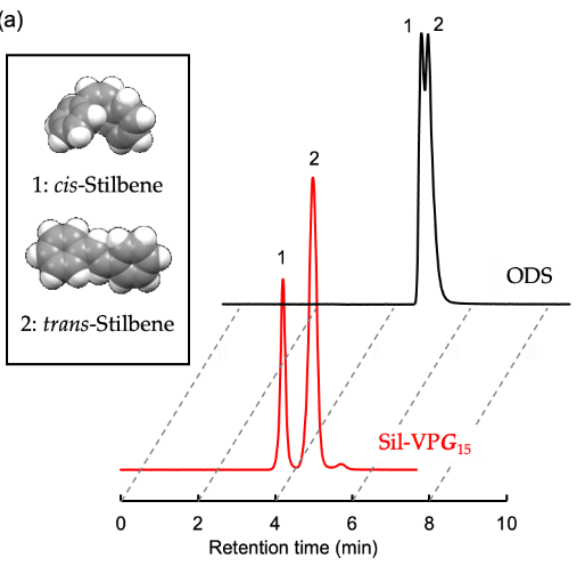

(b)

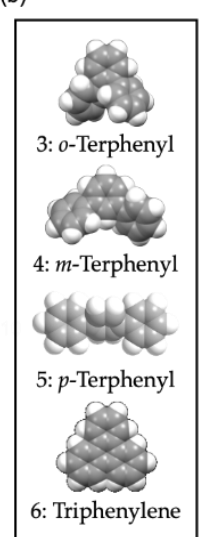

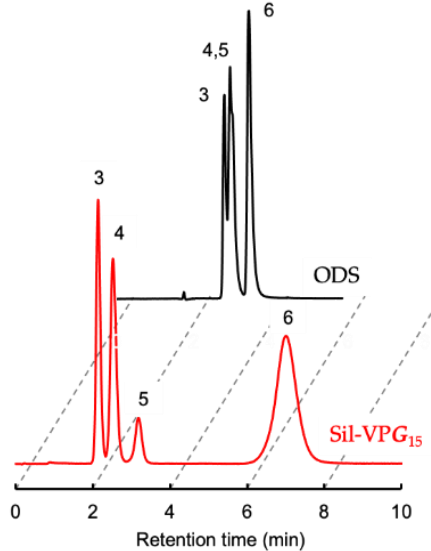

Figure 5. Chromatograms for (a) a mixture of cis-stilbene and trans-stilbene and (b) triphenylene and $o-, m-$, and $p$-terphenyls using Sil-VPG 15 and ODS as stationary phases. Mobile phase: Acetonitrile. Column temp.: $25^{\circ} \mathrm{C}$. Flow rate: $1.0 \mathrm{~mL} \mathrm{~min}^{-1}$.

Table 2. Retention factors $(\mathrm{k})$ and separation factors $(\alpha)$ of stilbene and terphenyl isomers using Sil-VPG 15 and ODS.

\begin{tabular}{|c|c|c|c|c|c|c|c|c|}
\hline \multirow{3}{*}{ Elutes } & \multicolumn{4}{|c|}{ Sil-VPG 15} & \multicolumn{4}{|c|}{ ODS } \\
\hline & \multicolumn{2}{|c|}{$0^{\circ} \mathrm{C}$} & \multicolumn{2}{|c|}{$50{ }^{\circ} \mathrm{C}$} & \multicolumn{2}{|c|}{$0^{\circ} \mathrm{C}$} & \multicolumn{2}{|c|}{$50{ }^{\circ} \mathrm{C}$} \\
\hline & k & $\alpha$ & k & $\alpha$ & k & $\alpha$ & k & $\alpha$ \\
\hline cis-Stilbene & 0.21 & - & 0.05 & - & 0.61 & - & 0.26 & - \\
\hline trans-Stilbene & 0.68 & 3.24 & 0.09 & 1.80 & 0.55 & $0.90(1.11)$ & 0.22 & $0.85(1.18)$ \\
\hline$o$-Terphenyl & 0.28 & - & 0.09 & - & 0.70 & - & 0.31 & - \\
\hline$m$-Terphenyl & 0.76 & 2.71 & 0.19 & 2.11 & 0.84 & 1.20 & 0.35 & 1.13 \\
\hline$p$-Terphenyl & 1.74 & 6.21 & 0.34 & 3.78 & 0.94 & 1.34 & 0.37 & 1.19 \\
\hline Triphenylene & 8.36 & 29.86 & 1.39 & 15.44 & 1.36 & 1.94 & 0.51 & 1.65 \\
\hline
\end{tabular}

Mobile phase: Acetonitrile. Flow rate: $1.0 \mathrm{~mL} \mathrm{~min}^{-1}$.
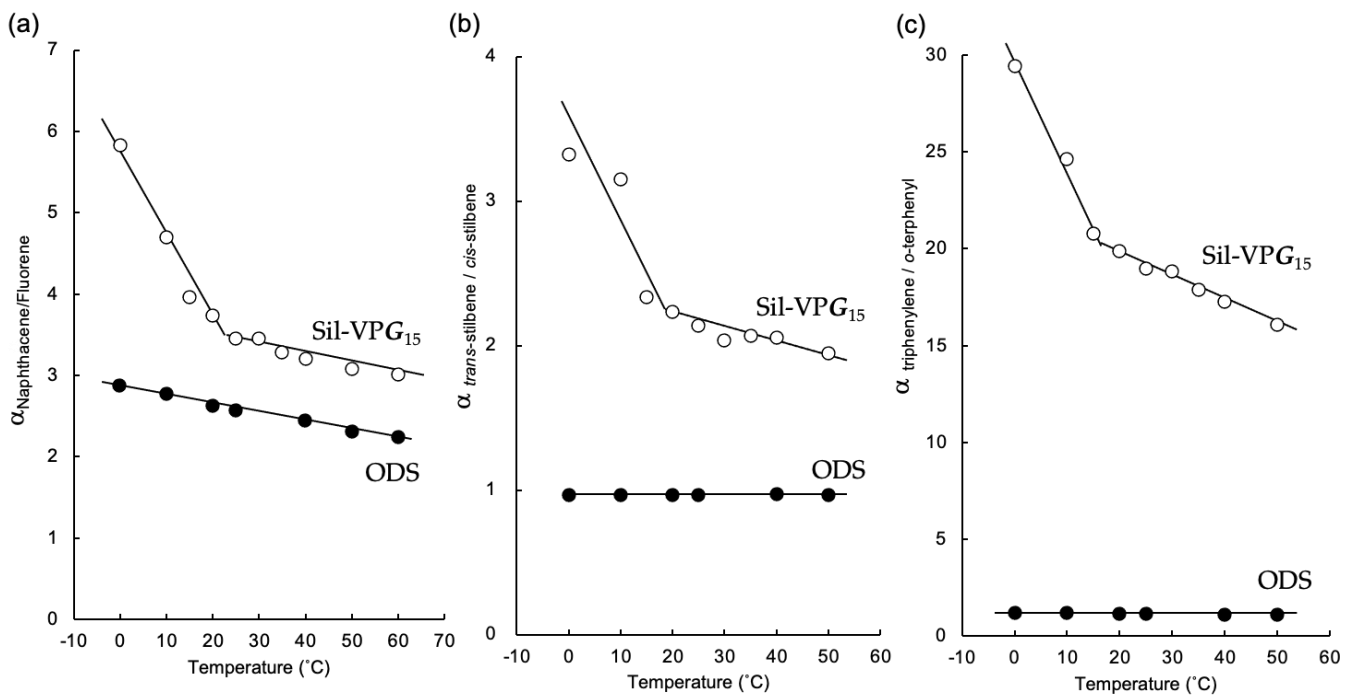

Figure 6. Temperature dependence of the separation factors for (a) naphthacene/fluorene, (b) trans-stilbene/cis-stilbene and (c) triphenylene/o-terphenyl using Sil-VPG 15 and ODS as stationary phases. Mobile phase: Acetonitrile. Column temp.: $25^{\circ} \mathrm{C}$. Flow rate: $1.0 \mathrm{~mL} \mathrm{~min}^{-1}$. 


\subsubsection{Selective Separations of Aromatic Compounds Having Hydrophilic Functional Groups}

Monosubstituted benzenes such as phenol, aniline, and benzoic acid, were examined for chromatographic separation using Sil-VPG ${ }_{15}$. As shown in Figure 7, the elution order was toluene (methyl group) < aniline (amino group) < phenol (hydroxyl group) < benzoic acid (carboxylic acid group). Benzoic acid probably did not elute as a result of electrostatic interaction with the pyridinium group on Sil-VPG 15 . All monosubstituted benzenes with a polar group eluted later than toluene, indicating that retention was determined by a hydrophilic interaction (HILIC)/RP mixed-mode mechanism. It is noticeable that the organic phase of the Sil- $\mathrm{VPG}_{15}$ recognized not only hydrophilic groups but also hydrophobic groups due to its amphiphilic nature.

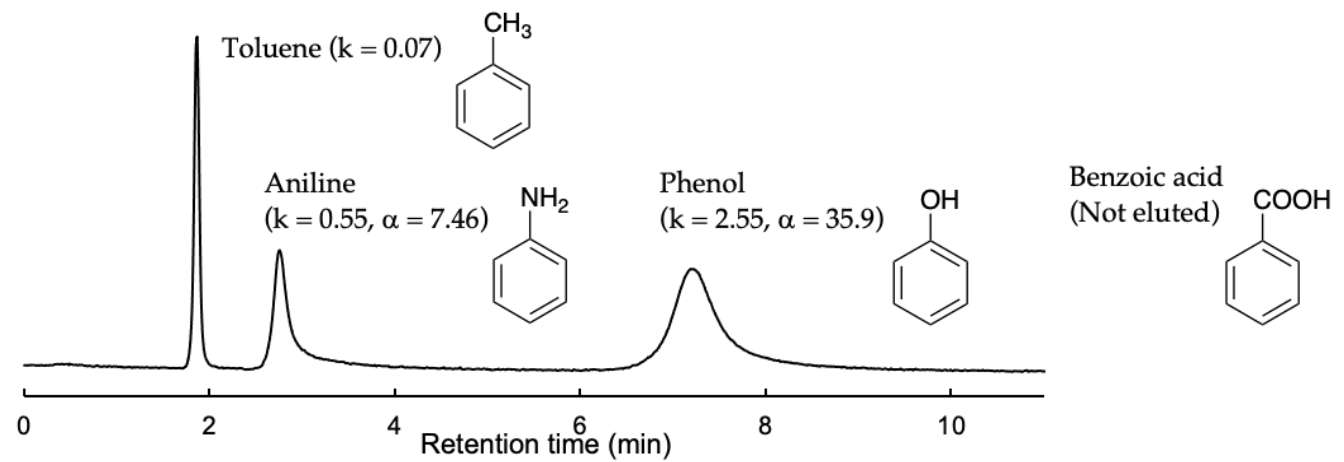

Figure 7. Chromatogram of toluene, aniline, phenol, and benzoic acid using Sil-VPG 15 . Mobile phase: Acetonitrile. Flow rate: $1.0 \mathrm{~mL} \mathrm{~min}^{-1}$. Temperature: $25^{\circ} \mathrm{C}$.

The positional isomers of monosubstituted phenols such as methyl phenols, dihydroxy benzenes, and aminophenols were also examined using Sil-VPG ${ }_{15}$. As shown in Table 3, the elution order of mono-substituted phenols was methylphenols $<$ aminophenols $<$ dihydroxybenzenes, which was the same as the order of the substitutional group of the monosubstituted benzenes described above. As expected, the Sil-VPG ${ }_{15}$ column recognized positional isomers of these substituted phenols.

Table 3. Retention factors $(\mathrm{k})$ and separation factors $(\alpha)$ of disubstituted benzenes using Sil-VPG 15 and ODS.

\begin{tabular}{lccc}
\hline \multirow{2}{*}{\multicolumn{1}{c}{ Elutes }} & \multicolumn{3}{c}{ Sil-VPG $\mathbf{1 5}$} \\
\cline { 2 - 4 } & $\mathbf{k}$ & $\boldsymbol{\alpha}$ & $\boldsymbol{\alpha}$ (vs. Phenol) \\
\hline Phenol & 2.55 & & - \\
\hline 2-Methyl phenol (o-isomer) & 2.37 & - & 0.93 \\
3-Methyl phenol ( $m$-isomer) & 2.18 & 0.92 & 0.86 \\
4-Methyl phenol ( $p$-isomer) & 2.66 & 1.22 & 1.04 \\
\hline 1,2-Dihydroxy benzene ( $o$-isomer) & 24.2 & - & 9.49 \\
1,3-Dihydroxy benzene $(m$-isomer) & 27.4 & 1.13 & 10.75 \\
1,4-Dihydroxy benzene ( $p$-isomer) & 34.4 & 1.42 & 13.49 \\
\hline 2-Aminophenol (o-isomer) & 12.4 & - & 4.86 \\
3-Aminophenol ( $m$-isomer) & 16.8 & 1.35 & 6.59 \\
4-Aminophenol ( $p$-isomer) & 24.2 & 1.95 & 9.49 \\
\hline
\end{tabular}

Mobile phase: Acetonitrile, Flow rate: $1.0 \mathrm{~mL} \mathrm{~min}{ }^{-1}$. Temperature: $25^{\circ} \mathrm{C}$.

\subsubsection{Application of Sil-VPG 15 Column to Separations of Steroids}

Steroids are amphiphilic compounds comprised of a skeleton of three hexagonal carbon rings and one pentagonal carbon ring, to which various functional groups such as hydroxyl are attached. Table 4 shows the retention and separation factors of eight 
steroids using a Sil- $\mathrm{VPG}_{15}$ column compared with those obtained via an ODS column. Sil-VPG 15 was able to separate the steroids based on their number of hydroxyl groups. The steroid (chemical structures are mentioned in the footnote of Table 4) elution order was: no hydroxyl groups (medroxyprogesterone acetate and progesterone) < one hydroxyl group (norethisterone, mestranol, and estrone) $<$ two hydroxyl groups $(17-\alpha$-ethinylestradiol and estradiol) < three hydroxyl groups (prednisolone). The separation factors increased significantly as the number of hydroxyl groups increased.

Table 4. Retention factors $(\mathrm{k})$ and separation factors $(\alpha)$ of steroids using Sil-VPG 15 and ODS.

\begin{tabular}{lcccc}
\hline \multirow{2}{*}{ Elutes $^{\mathbf{1}}$} & \multicolumn{2}{c}{ Sil- $\mathbf{V P G}_{\mathbf{1 5}}$} & \multicolumn{2}{c}{ ODS } \\
\cline { 2 - 5 } & $\mathbf{k}$ & $\boldsymbol{\alpha}$ & $\mathbf{k}$ & $\boldsymbol{\alpha}$ \\
\hline Medroxyprogesterone acetate & 0.07 & 0.27 & 0.48 & $0.71(1.42)$ \\
Progesterone & 0.26 & 1.00 & 0.68 & 1.00 \\
Norethisterone & 0.81 & 3.11 & 0.26 & $0.38(2.62)$ \\
Mestranol & 1.16 & 4.48 & 0.39 & $0.57(1.74)$ \\
Estrone & 4.06 & 15.7 & 0.22 & $0.32(3.09)$ \\
17- $\alpha$-Ethinylestradiol & 12.3 & 47.6 & 0.14 & $0.21(4.86)$ \\
Estradiol & 14.2 & 54.7 & 0.29 & $0.43(2.34)$ \\
Prednisolone & 22.8 & 87.7 & 0.12 & $0.18(5.67)$ \\
\hline
\end{tabular}

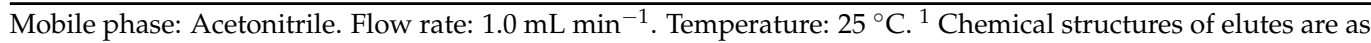
follows.
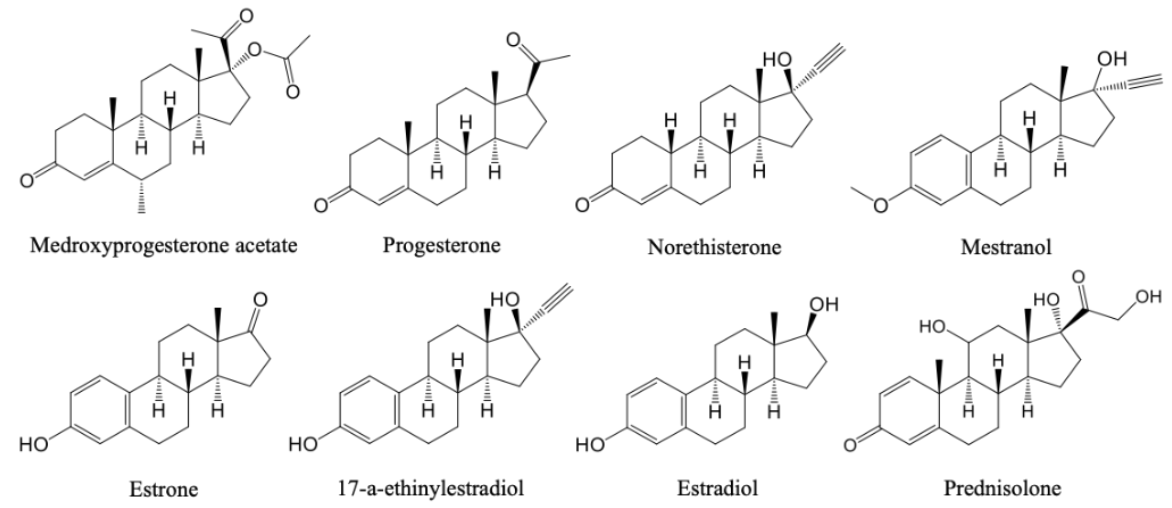

\section{Conclusions}

Amphiphilic glutamide was successfully introduced as a self-assembling molecular gel to the side chain of a terminally grafted poly(4-vinylpyridine) on the surface of porous silica microspheres. The $G$ moieties formed a highly ordered structure and showed phase transitions at $23.1^{\circ} \mathrm{C}$ (pre-phase transition) and at $42.4^{\circ} \mathrm{C}$ (main phase transition) in an acetonitrile suspension even on the surface of a solid substrate. Compared with a conventional ODS column, Sil-VPG 15 showed high selectivity toward PAHs, and particularly excellent separations were obtained for geometrical and positional isomers such as stilbenes and triphenylenes. This separation ability is probably due to multiple interactions between the elutes and functional groups on the highly oriented $G$ moiety of the organic phase, such as pyridinium and amide bonding. Furthermore, Sil-VPG 15 recognized substituted benzenes in the order of toluene (methyl group) < aniline (amine group) $<$ phenol (hydroxyl group) < benzoic acid (carboxylic acid). Highly selective separations were obtained for positional isomers of phenolic compounds such as methyl phenols, dihydroxy benzenes, and aminophenols. We also demonstrated the separation of eight steroid compounds having different chemical structures and different numbers of hydroxyl groups. Isolation and purification of biological molecules such as peptides, proteins, saccharides and nucleosides are indispensable technology in the fields of proteomics, genomics, and glycomics [40-42]. Further study for the separation of bio-related molecules using Sil-VPG 15 is currently underway and will be reported in the future. 
Author Contributions: Conceptualization, M.T. and H.I.; methodology, M.T.; validation, N.K., Y.K., H.I. and M.T.; formal analysis, N.K. and Y.H.; investigation, N.K. and Y.H.; data curation, N.K. and M.T.; writing - original draft preparation, M.T. and N.K.; writing-review and editing, H.I. and Y.K.; visualization, N.K. and M.T.; supervision, M.T. and H.I.; funding acquisition, H.I and M.T. All authors have read and agreed to the published version of the manuscript.

Funding: This work was partially supported by a Grant-in-Aid for Scientific Research (KAKENHI) from the Japan Society for the Promotion of Science (JSPS), Japan, and Bilateral Joint Research Projects from JSPS, Japan.

Institutional Review Board Statement: Not applicable.

Informed Consent Statement: Not applicable.

Conflicts of Interest: The authors declare no conflict of interest.

\section{References}

1. Shi, X.; Qiao, L.; Xu, G. Recent development of ionic liquid stationary phases for liquid chromatography. J. Chromatogr. A 2015, 1420, 1-15. [CrossRef]

2. Wang, Q.; Baker, G.A.; Bakerc, S.N.; Colón, L.A. Surface confined ionic liquid as a stationary phase for HPLC. Analyst 2006, 131, 1000-1005. [CrossRef]

3. Sun, M.; Feng, J.; Chen, W.; Li, L.; Duan, H.; Luo, C. Improvement of the chromatographic separation performance of an imidazolium ionic liquid functionalized silica column by in situ anion-exchange with dodecyl sulfonate and dodecylbenzene sulfonate anions. J. Sep. Sci. 2014, 37, 1283-1288. [CrossRef]

4. Qiao, L.; Dou, A.; Shi, X.; Li, H.; Shan, Y.; Lu, X.; Xu, G. Development and evaluation of new imidazolium-based zwitterionic stationary phases for hydrophilic interaction chromatography. J. Chromatogr. A 2013, 1286, 137-145. [CrossRef] [PubMed]

5. Qiu, H.; Liang, X.; Sun, M.; Jiang, S. Development of silica-based stationary phases for high-performance liquid chromatography. Anal. Bioanal. Chem. 2011, 399, 3307-3322. [CrossRef] [PubMed]

6. Hu, Y.; Cai, T.; Zhang, H.; Chen, J.; Li, Z.; Zhao, L.; Li, Z.; Qiu, H. Two copolymer-grafted silica stationary phases prepared by surface thiol-ene click reaction in deep eutectic solvents for hydrophilic interaction chromatography. J. Chromatogr. A 2020, 1609, 460446-460454. [CrossRef] [PubMed]

7. Hu, Y.; Cai, T.; Zhang, H.; Chen, J.; Li, Z.; Qiu, H. Poly(itaconic acid)-grafted silica stationary phase prepared in deep eutectic solvents and its unique performance in hydrophilic interaction chromatography. Talanta 2019, 191, 265-271. [CrossRef] [PubMed]

8. Skoczylas, M.; Bociana, S.; Buszewski, B. Dipeptide-bonded stationary phases for hydrophilic interaction liquid chromatography. RSC Adv. 2016, 6, 96389-96397. [CrossRef]

9. Ray, S.; Takafuji, M.; Ihara, H. Chromatographic evaluation of a newly designed peptide-silica stationary phase in reverse phase liquid chromatography and hydrophilic interaction liquid chromatography: Mixed mode behavior. J. Chromatogr. A 2012, 1266, 43-52. [CrossRef]

10. Ohyama, K.; Inoue, Y.; Kishikawa, N.; Kuroda, N. Preparation and characterization of surfactin-modified silica stationary phase for reversed-phase and hydrophilic interaction liquid chromatography. J. Chromatogr. A 2014, 1371, 257-260. [CrossRef] [PubMed]

11. Lu, T.; Olesik, S.V. Homogeneous edge-plane carbon as stationary phase for reversed-phase liquid chromatography. Anal. Chem. 2015, 87, 3616-3622. [CrossRef]

12. Noguchi, H.; Sultana, M.; Hano, N.; Kuwahara, Y.; Takafuji, M.; Nagaoka, S.; Qiu, H.; Ihara, H. Fabrication of carbon-like, $\pi$-conjugated organic layer on a nano-porous silica surface. Nanomaterials 2020, 10, 1882. [CrossRef]

13. Candelaria1, L.; Frolova, L.V.; Kowalski, B.M.; Artyushkova, K.; Serov, A.; Kalugin, N.G. Surface-modified three-dimensional graphene nanosheets as a stationary phase for chromatographic separation of chiral drugs. Sci. Rep. 2018, 8, 14747. [CrossRef] [PubMed]

14. Sander, L.C.; Wise, S.A. Synthesis and characterization of polymeric C18 stationary phases for liquid chromatography. Anal. Chem. 1984, 56, 504-510. [CrossRef]

15. Jinno, K.; Nagoshi, T.; Tanaka, N.; Okamoto, M.; Fetzer, J.C.; Biggs, W.R. Eluation behaviour of planar and non-planar polycyclic aromatic hydrocarbons on various chemically bonded stationary phases in liquid chromatography. J. Chromatogr. A 1987, 392, 75-82. [CrossRef]

16. Weiss, R.G.; Terech, P. (Eds.) Molecular Gels; Springer: Berlin, Germany, 2006.

17. Ihara, H.; Takafuji, M.; Kuwahara, Y. Polymer functionalization by luminescent supramolecular gel. Polym. J. 2016, 48, 843-853. [CrossRef]

18. Shimizu, T.; Masuda, M.; Minamikawa, H. Supramolecular nanotube architectures based on amphiphilic molecules. Chem. Rev. 2005, 105, 1401-1444. [CrossRef]

19. Ihara, H.; Takafuji, M.; Kuwahara, Y.; Okazaki, Y.; Ryu, N.; Sagawa, T.; Oda, R. Luminescent supramolecular gel for light management technology. In Molecular Technology; Yamamoto, H., Kato, T., Eds.; Wiley: Hoboken, NJ, USA, 2019; Volume 4, pp. 297-337.

20. Weiss, R.G. (Ed.) Molecular Gels: Structure and Dynamics; Royal Society of Chemistry: Cambridge, UK, 2018. 
21. Escuder, B.; Miravet, J.F. (Eds.) Functional Molecular Gels; Royal Society of Chemistry: Cambridge, UK, 2014.

22. Goto, T.; Okazaki, Y.; Ueki, M.; Kuwahara, Y.; Takafuji, M.; Oda, R.; Ihara, H. Induction of strong and tunable circularly polarized luminescence of non-chiral, non-metal, low-molecular-weight fluorophores using chiral nano-template. Angew. Chem. Int. Ed. 2017, 56, 2989-2993. [CrossRef] [PubMed]

23. Takafuji, M.; Kawahara, T.; Sultana, N.; Ryu, N.; Yoshida, K.; Kuwahara, Y.; Oda, R.; Ihara, H. Extreme enhancement of secondary chirality through coordination-driven steric changes of terpyridyl ligand in glutamide-based molecular gels. RSC Adv. 2020, 10, 29627-29632. [CrossRef]

24. Oishi, H.; Mashima, S.; Kuwahara, Y.; Takafuji, M.; Yoshida, K.; Oda, R.; Qiu, H.; Ihara, H. Polymer encapsulation and stabilization of molecular gel- based chiroptical information for strong, tunable circularly polarized luminescence film. J. Mater. Chem. C 2020, 8, 8732-8735. [CrossRef]

25. Yoshida, K.; Kuwahara, Y.; Miyamoto, K.; Nakashima, S.; Jintoku, H.; Takafuji, M.; Ihara, H. A room-temperature phosphorescent polymer film containing a molecular web based on one-dimensional chiral stacking of a simple luminophore. Chem. Commun. 2017, 53, 5044-5047. [CrossRef]

26. Ihara, H.; Takafuji, M.; Hirayama, C.; O’Brien, D.F. Effect of photopolymerization on the morphology of helical supramolecular assemblies. Langmuir 1992, 8, 1548-1553. [CrossRef]

27. Kira, Y.; Okazaki, Y.; Sawada, T.; Takafuji, M.; Ihara, H. Amphiphilic molecular gels from omega-aminoalkylated L-glutamic acid derivatives with unique chiroptical property. Amino Acids 2010, 39, 587-697. [CrossRef] [PubMed]

28. Takafuji, M.; Kira, Y.; Tsuji, H.; Sawada, S.; Hachisako, H.; Ihara, H. Optical active polymer film tuned by chirally self-assembled molecular organogel. Tetrahedron 2007, 63, 7489-7494. [CrossRef]

29. Rahman, M.M.; Takafuji, M.; Ansarian, H.R.; Derakhshan, M.; Ihara, H. Enhanced molecular shape selectivity through multiple carbonyl-p interaction with noble non-crystalline solid phase for RP-HPLC. Anal. Chem. 2005, 77, 6671-6681. [CrossRef]

30. Takafuji, M.; Rahman, M.M.; Ansarian, H.R.; Derakhshan, M.; Sakurai, T.; Ihara, H. Dioctadecyl L-glutamide-derived lipid-grafted silica as a novel organic stationary phase for RP-HPLC. J. Chromatogr. A 2005, 1074, 223-228. [CrossRef]

31. Noguchi, H.; Charoenraks, T.; Takafuji, M.; Ihara, H. Effects of substitution groups of glutamide-derived molecular gels on molecular shape recognition. J. Chromatogr. A 2015, 1392, 56-62. [CrossRef]

32. Rahman, M.M.; Takafuji, M.; Ihara, H. Evaluation of selectivity for L-glutamide-derived highly ordered assemblies in reversedphase high-performance liquid Chromatography. Talanta 2009, 77, 1228-1237. [CrossRef] [PubMed]

33. Gopal, V.; Prasad, T.K.; Rao, N.M.; Takafuji, M.; Rahman, M.M.; Ihara, H. Synthesis and in vitro evaluation of glutamidecontaining cationic lipids for gene delivery. Bioconjugate Chem. 2006, 17, 1530-1536. [CrossRef]

34. Ihara, H.; Nagaoka, S.; Tanaka, H.; Sakaki, S.; Hirayama, C. Lipid membrane analogue-immobilized silica gels for separation with molecular recognition. J. Liq. Chromatogr. 1996, 19, 2967-2984. [CrossRef]

35. Biesalski, M.; Ruhe, J. Swelling of a polyelectrolyte brush in humid air. Langmuir 2000, 16, 1943-1950. [CrossRef]

36. Takafuji, M.; Mimaki, T.; Xu, Z.; Ihara, H. Surface charge controlled magnetic nanoparticles with grafting of poly(4-vinylpyridine). J. Nanosci. Nanotechnol. 2005, 5, 394-397. [CrossRef] [PubMed]

37. Hirayama, C.; Ihara, H.; Mukai, T. Lipid membrane analogues. Specific retention behavior in comb-shaped telomer-immobilized porous silica gels. Macromolecules 1992, 25, 6375-6376. [CrossRef]

38. Ihara, H.; Goto, Y.; Sakurai, T.; Takafuji, M.; Sagawa, T.; Nagaoka, S. Enhanced molecular-shape selectivity for polyaromatic hydrocarbons through isotropic-to-crystalline phase transition of poly(octadecyl acrylate). Chem. Lett. 2001, 30, 1252-1253. [CrossRef]

39. Ihara, H.; Fukui, M.; Mimaki, T.; Shundo, A.; Dong, W.; Derakhshan, M.; Sakurai, T.; Takafuji, M.; Nagaoka, S. Poly(4vinylpyridine) as a novel organic end-capping reagent for silica and its specific selectivity for PAHs and dinitropyrenes in a reversed phase. Anal. Chim. Acta. 2005, 548, 51-57. [CrossRef]

40. Rodriguez, E.L.; Poddar, S.; Iftekhar, S.; Suh, K.; Woolfork, A.G.; Ovbude, S.; Pekarek., A.; Walters, M.; Lott, S.; Hage, D.S. Affinity chromatography: A review of trends and developments over the past 50 years. J. Chromatogr. B 2020, 1157, 122332. [CrossRef]

41. Kip, C.; Hamaloğlu, K.O.; Demir, C.; Tuncel., A. Recent trends in sorbents for bioaffinity chromatography. J. Sep. Sci. 2021, 44, 1273-1291. [CrossRef]

42. Maekawa, Y.; Yamazaki, K.; Ihara, M.; Nagase, K.; Kanazawa, H. Simultaneous analysis of multiple oligonucleotides by temperature-responsive chromatography using a poly(N-isopropylacrylamide)-based stationary phase. Anal. Bioanal. Chem. 2020, 412, 5341-5351. [CrossRef] [PubMed] 